\title{
Genome-wide analysis identifies a functional association of Tet 1 and Polycomb repressive complex 2 in mouse embryonic stem cells
}

\author{
Francesco Neri', Danny Incarnato ${ }^{1,2}$, Anna Krepelova ${ }^{1,2}$, Stefania Rapelli ${ }^{1,2}$, Andrea Pagnani ${ }^{1,3}$, Riccardo Zecchina ${ }^{1,3}$, \\ Caterina Parlato ${ }^{1}$ and Salvatore Oliviero ${ }^{1,2^{*}}$
}

\begin{abstract}
Background: Ten-Eleven Translocation (TETs)proteins mediate the oxidation of 5-methylcytosine (5mC) to 5hydroxymethylcytosine (5hmC). Tet1 is expressed at high levels in mouse embryonic stem cells (ESCs), where it mediates the induction of $5 \mathrm{hmC}$ decoration on gene-regulatory elements. While the function of Tet 1 is known, the mechanisms of its specificity remain unclear.

Results: We perform a genome-wide comparative analysis of $5 \mathrm{hmC}$ in pluripotent ESCs, as well as in differentiated embryonic and adult cells. We find that $5 \mathrm{hmC}$ co-localization with Polycomb repressive complex 2 (PRC2) is specific to ESCs and is absent in differentiated cells. Tet1 in ESCs is distributed on bivalent genes in two independent pools: one with Sin3a centered at non-hydroxymethylated transcription start sites and another centered downstream from these sites. This latter pool of Tet1 co-localizes with 5hmC and PRC2. Through coimmunoprecipitation experiments, we show that Tet1 forms a complex with PRC2 specifically in ESCs. Genomewide analysis of 5hmC profiles in ESCs following knockdown of the PRC2 subunit Suz12 shows a reduction of $5 \mathrm{hmC}$ within promoter sequences, specifically at H3K27me3-positive regions of bivalent promoters.

Conclusions: In ESCS, PRC2 recruits Tet1 to chromatin at H3K27me3 positive regions of the genome, with 5hmC enriched in a broad peak centered $455 \mathrm{bp}$ after the transcription start site and dependent on the PRC2 component Suz12. These results suggest that PRC2-dependent recruitment of Tet1 contributes to epigenetic plasticity throughout cell differentiation.
\end{abstract}

Keywords: DNA-hydrossymethylation, Chip-Seq, PRC2, Stem Cells, Liver, Brain;Fibroblasts

\section{Background}

In eukaryotic cells, 5-methylcytosine $(5 \mathrm{mC})$ occurs almost exclusively within a CpG context, and is catalyzed by the family of DNA methyltransferase (DNMT) enzymes [1-3]. More recently, a number of studies have identified a mechanism of DNA demethylation involving the oxidation of $5 \mathrm{mC}$ to 5 -hydroxymethylcytosine $(5 \mathrm{hmC})$, which can function as a new epigenetic marker or as an intermediate toward further oxidative states by Ten-eleven translocation (TET) proteins [4-11]. In embryonic stem cells (ESCs) and in embryonic and adult tissues, $5 \mathrm{hmC}$ modification occurs at high levels, whereas

\footnotetext{
* Correspondence: oliviero.salva@gmail.com

${ }^{1}$ Human Genetics Foundation (HuGeF), via Nizza 52, 10126, Torino, Italy Full list of author information is available at the end of the article
}

it is significantly reduced in cancer[12-17]. In ESCs, $5 \mathrm{hmC}$ is principally catalyzed by Tet1, which has high expression in these cells. Genome-wide studies in ESCs have shown $5 \mathrm{hmC}$ enrichment on regulatory elements, such as promoters, enhancers, and gene bodies [18-27]. Tet1 depletion in ESCs leads to both transcriptional activation, in accordance with its role in oxidation of $5 \mathrm{mC}$, and transcriptional repression [6,20,25,28-32]. Genome-wide analysis have shown that Tet1 binding correlates with the transcriptional repressor Sin3a, which forms a nuclear complex with Tet1 and also with the Polycomb repressive complex 2 (PRC2) [19,23,25,32].

PRC2 is the enzymatic complex that mediates the trimethylation of lysine 27 of histone H3 (H3K27me3) on developmental genes that determine whether the chromatin

\section{Biomed Central}

() 2013 Neri et al.; licensee BioMed Central Ltd. This is an open access article distributed under the terms of the Creative Commons Attribution License (http://creativecommons.org/licenses/by/2.0), which permits unrestricted use, distribution, and reproduction in any medium, provided the original work is properly cited. 
remains either open or fully inaccessible. It is formed by a core complex that includes Enhancer of Zeste 1 or 2 homolog (Ezh1 or Ezh2), Suppressor of Zeste 12 homolog (Suz12), Embryonic ectoderm development (Eed), and other accessory subunits, many of which are specific to ESCs [33-41]. PRC2 is involved in a number of different biological processes, and its dysregulation is associated with carcinogenesis [33,42].

Using genome-wide analysis of $5 \mathrm{hmC}$ distribution in ESCs with respect to embryonic and adult tissues, we found that the overlap between the repressive modification H3K27me3 and 5hmC is ESC-specific, and we studied the molecular mechanism of the interplay between Tet 1 and $\mathrm{PRC} 2$ in ESC.

\section{Results}

\section{Genome-wide distribution of 5hmC in ESCs and} differentiated cells

We mapped the genome-wide distribution of $5 \mathrm{hmC}$ using the glucosylation, periodate oxidation, biotinylation (GLIB) method followed by sequencing using an Illumina platform (GLIB-Seq) [18] in ESCs, primary mouse embryonic fibroblasts (MEFs), and two different tissues with distinct embryological derivation: brain, which is known to have high levels of $5 \mathrm{hmC}$, and liver, which is a homogeneous tissue composed almost exclusively of hepatocytes.

Heatmaps plotted using the gene expression levels obtained from RNA sequencing (RNA-Seq) analysis showed a similar distribution pattern in all samples, with $5 \mathrm{hmC}$ enrichment typically on gene bodies with respect to the transcription start site (TSS) (Figure 1A). Classification of the genes by their level of expression showed an enrichment of $5 \mathrm{hmC}$ on upstream promoter regions and the gene bodies of genes with higher expression. By contrast, unexpressed genes or genes expressed at low levels showed an enrichment of $5 \mathrm{hmC}$ at the TSS, which was more evident in undifferentiated ESCs (Figure 1B). To further investigate the relationship between hydroxymethylation and tissue specificity, we analyzed the distribution of $5 \mathrm{hmC}$ for genes expressed in the liver by separating them in two groups: liver-specific genes and housekeeping genes. Notably, liver-specific genes showed $5 \mathrm{hmC}$ enrichment only on the upstream region and along the genes in the liver itself, whereas they showed increased $5 \mathrm{hmC}$ at the TSSs in ESCs, MEFs, and brain tissue (Figure 1C, left panels). Conversely, the housekeeping genes in all cell types had $5 \mathrm{hmC}$ distributed at upstream promoter regions and in the gene bodies but not at the TSS (Figure 1C, right panels).

For each cell type, we then plotted the expression level (reads per $\mathrm{kb}$ of exon per million mapped reads (RPKM) $\log 10)$ and the $5 \mathrm{hmC}$ intensity normalized for the gene length for each gene to further clarify the role of $5 \mathrm{hmC}$ in gene expression (see Additional file 1 Figure S1). This analysis identified $5 \mathrm{hmC}$ enrichment at genes with medium expression levels, with a peak around RPKM $\log 10$ value $=1$ (Figure 1C), whereas genes that were not expressed (RPKM $\log 10$ value $<-1$ ) or expressed at very high levels (RPKM $\log 10$ value $\geq 3$ ) showed little or no $5 \mathrm{hmC}$.

The examples (see Additional file 1: Figure S1) show the $5 \mathrm{hmC}$ distribution and transcript levels of the Pou5f1 and Albumin genes, which are highly expressed in ESCs and liver, respectively, and Eef1a1, which is highly expressed in all four cell types. Taken together, these results show that $5 \mathrm{hmC}$ is enriched on the TSSs of genes that are not expressed or are expressed at low levels, whereas genes that are more highly expressed show an enrichment of $5 \mathrm{hmC}$ along the gene but not at TSSs, independent of the cell type.

\section{5hmC correlates with PRC2 and H3K27me3 in ESCs, but not in differentiated cells}

Recent studies in ESCs have highlighted 5hmC enrichment on specific genomic elements and in association with some histone modifications [18-20,24-26,29,32]. We extended this analysis by comparing ESCs with differentiated MEFs, and brain and liver tissues. Analysis of $5 \mathrm{hmC}$ density on promoters and gene bodies normalized according to base pair length showed that $5 \mathrm{hmC}$ was significantly enriched on promoters in ESCs but not in differentiated cells,(Figure 2A).

As previously observed, the exons in ESCs showed higher levels of DNA hydroxymethylation than did the introns, and this difference was confirmed in the other cell types we analyzed (Figure 2B). By contrast, the DNA of active enhancers was enriched by hydroxymethylation in ESCs, whereas this correlation was inverted in differentiated cells (Figure 2C). We also found significant $5 \mathrm{hmC}$ enrichment in promoters with low or intermediate $\mathrm{CpG}$ content (LCP and ICP, respectively) compared with high CpG (HCP) content in all cell types analyzed (Figure 2D).

Importantly, we found strong enrichment of $5 \mathrm{hmC}$ on H3K4me3K27me3 double-positive and H3K27me3positive promoters compared with $\mathrm{H} 3 \mathrm{~K} 4 \mathrm{me} 3$-positive promoters in ESCs but not in the other cell types (Figure $2 \mathrm{E})$. Further comparison of our data with published histone modifications and transcription factor occupancy confirmed that, in ESCs, $5 \mathrm{hmC}$ co-localizes with $\mathrm{H} 3 \mathrm{~K} 27 \mathrm{me} 3$, as well as with Ezh2 and Suz12 binding (Figure 2F; see Additional file 1: Figure $\mathrm{S} 2$ )

Analysis of the genome-wide distribution of $5 \mathrm{hmC}$ and $\mathrm{H} 3 \mathrm{~K} 27 \mathrm{me} 3$ at promoters $( \pm 5 \mathrm{~kb})$ of all genes, ordered by expression level, showed that H3K27me3 is more abundant on promoters of genes with low expression in all cell types. However, in ESCs only, H3K27me3 promoters showed a significant enrichment of $5 \mathrm{hmC}$ (Figure 3A,B). 


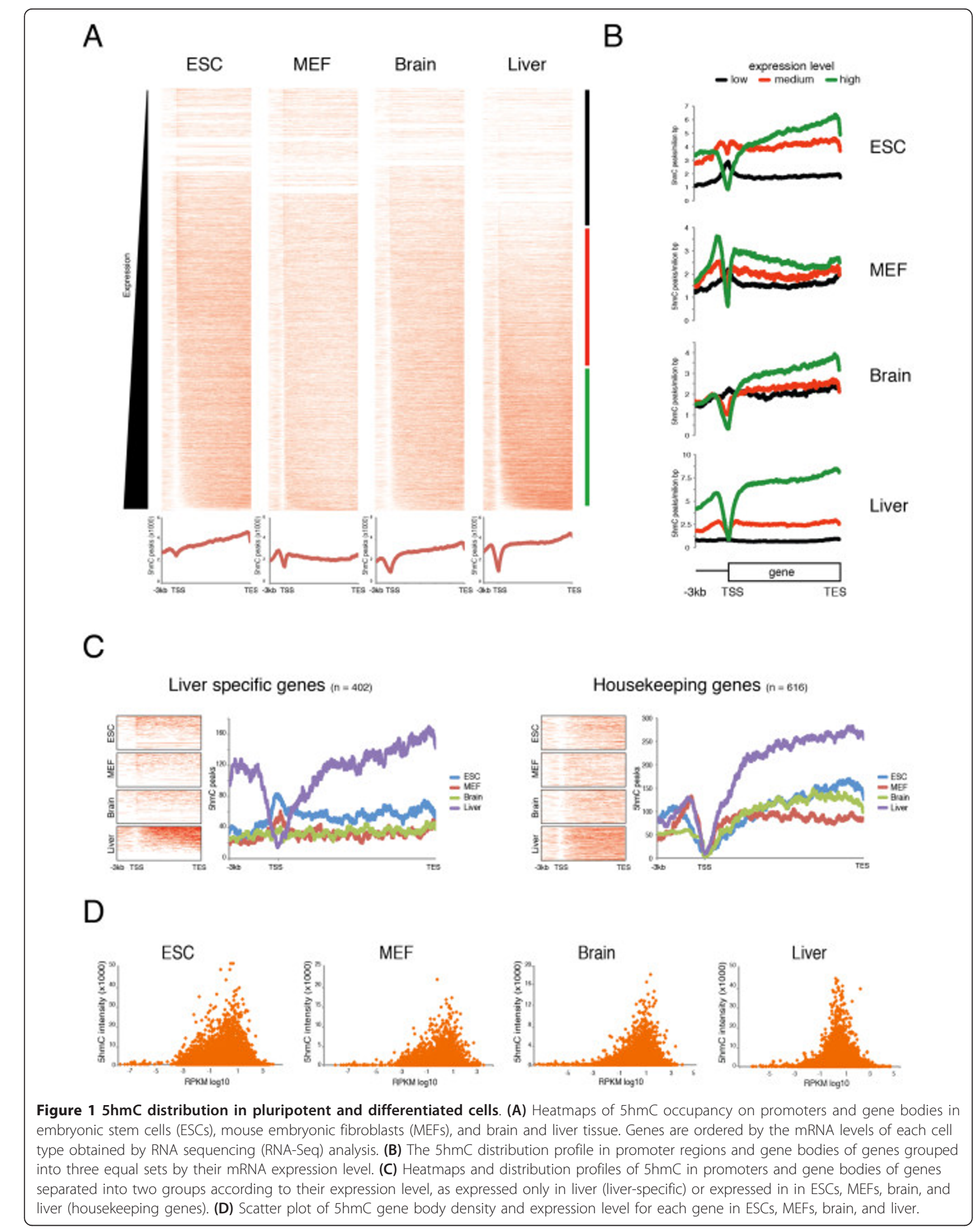

B 


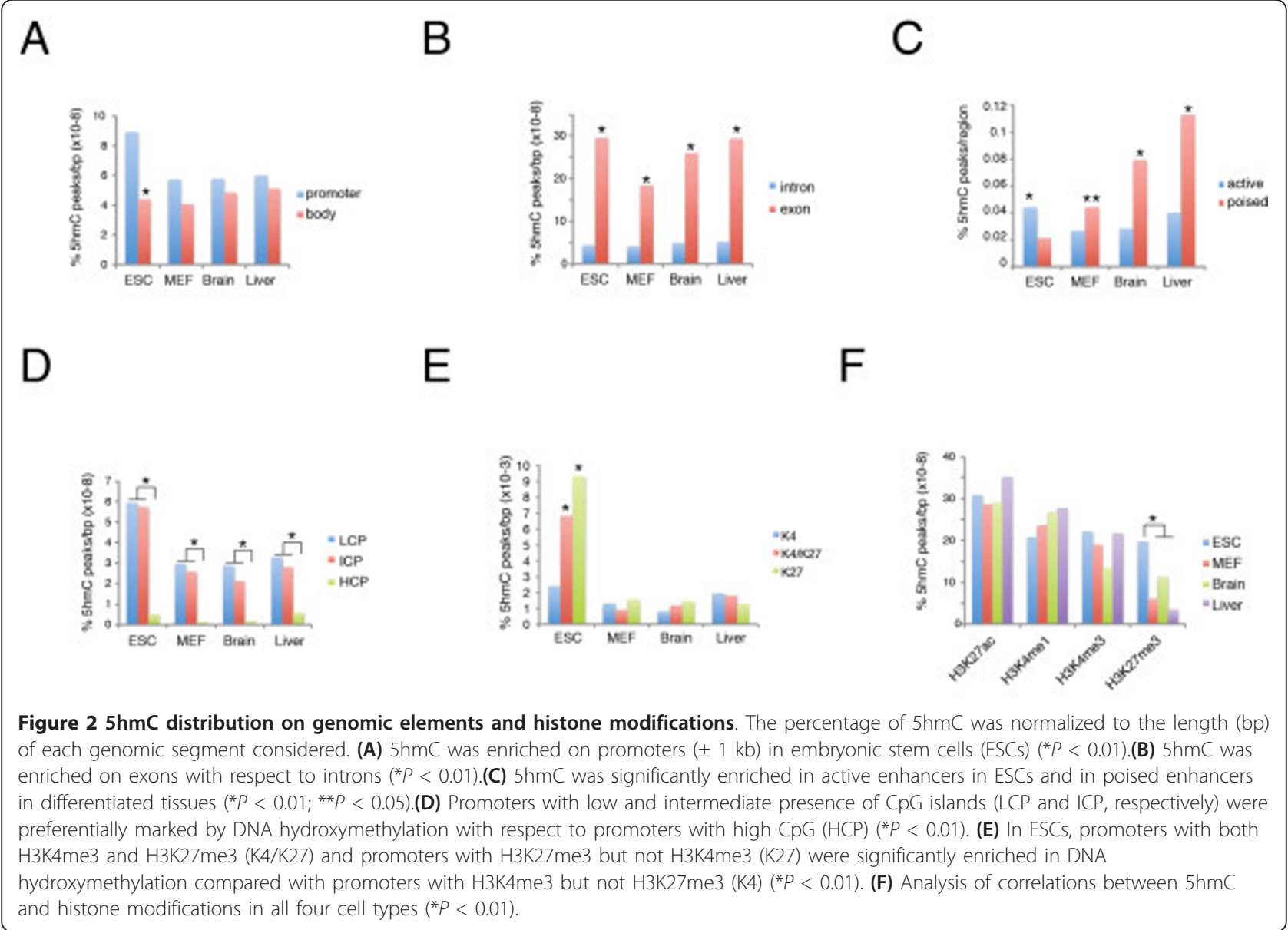

\section{Tet1 bimodal binding profile in H3K27me3 positive} promoters

The above data show a correlation between $5 \mathrm{hmC}$ and H3K27me3 distribution on ESC promoters. Further analysis of Tet1 distribution, using published chromatin immunoprecipitation sequencing (ChIP-Seq) datasets [25][32], on genes ordered by level of H3K27me3, showed that Tet1 binding correlates with Ezh2 and Suz12, as well as with Sin3a, a protein recently discovered in complex with Tet1 [25] (Figure 4A). Approximately $84 \%$ of Suz12 and $47 \%$ of Sin3a binding sites were also bound by Tet1, whereas the overlap between Sin3a and Suz12 was low (see Additional file 1, Figure S3).

Moreover, Tet1-Sin3a co-bound peaks showed high $\mathrm{CpG}$ island content, whereas the number of $\mathrm{CpG}$ islands was significantly decreased in Tet1-H3K27me3 co-bound regions (see Additional file 1, Figure S3).

Using unsupervised analysis of Tet1 binding, with a k-means clustering algorithm based on the Pearson correlation coefficient across profiles, we generated binding profile curves across each promoter $( \pm 5 \mathrm{~kb})$. After separating the results into two clusters $(k=2)$, we obtained two different Tet1 binding profiles: cluster 1 , with a profile centered on the TSS and enriched at K4only genes; and cluster 2 , with a larger profile centered downstream from the TSS enriched on bivalent promoters (Figure 4B). Next, we plotted the Tet1 peaks around the TSS. On H3K27me3-negative genes, the Tet1 binding overlapped with Sin3a (Figure 4C, upper panel). Interestingly, on H3K27me3-positive genes, Tet1 displayed a bimodal profile that correlated with Sin3a on the TSS and with Suz12 downstream of the TSS (Figure 4C, lower panel). Fitting the Tet1 binding curve on the TSS ( $\pm 5 \mathrm{~kb}$ ) using a superposition of two Gaussian distributions (six parameters fit, see Methods) showed that the first Gaussian curve was narrower and centered $39 \mathrm{bp}$ upstream of the TSS, whereas the second was broader and centered 455 bp downstream of the TSS (Figure 4D). Taken together, these data suggest that Tet1 is present on bivalent genes in two distinct pools, one overlapping with Sin3a and the other with Suz12.

PRC2 interacts with Tet1 in ESC, and its binding is required for DNA hydroxymethylation at bivalent genes The data above suggest interplay between Tet 1 and PRC2 in ESCs. Next, we examined whether Tet1 could 


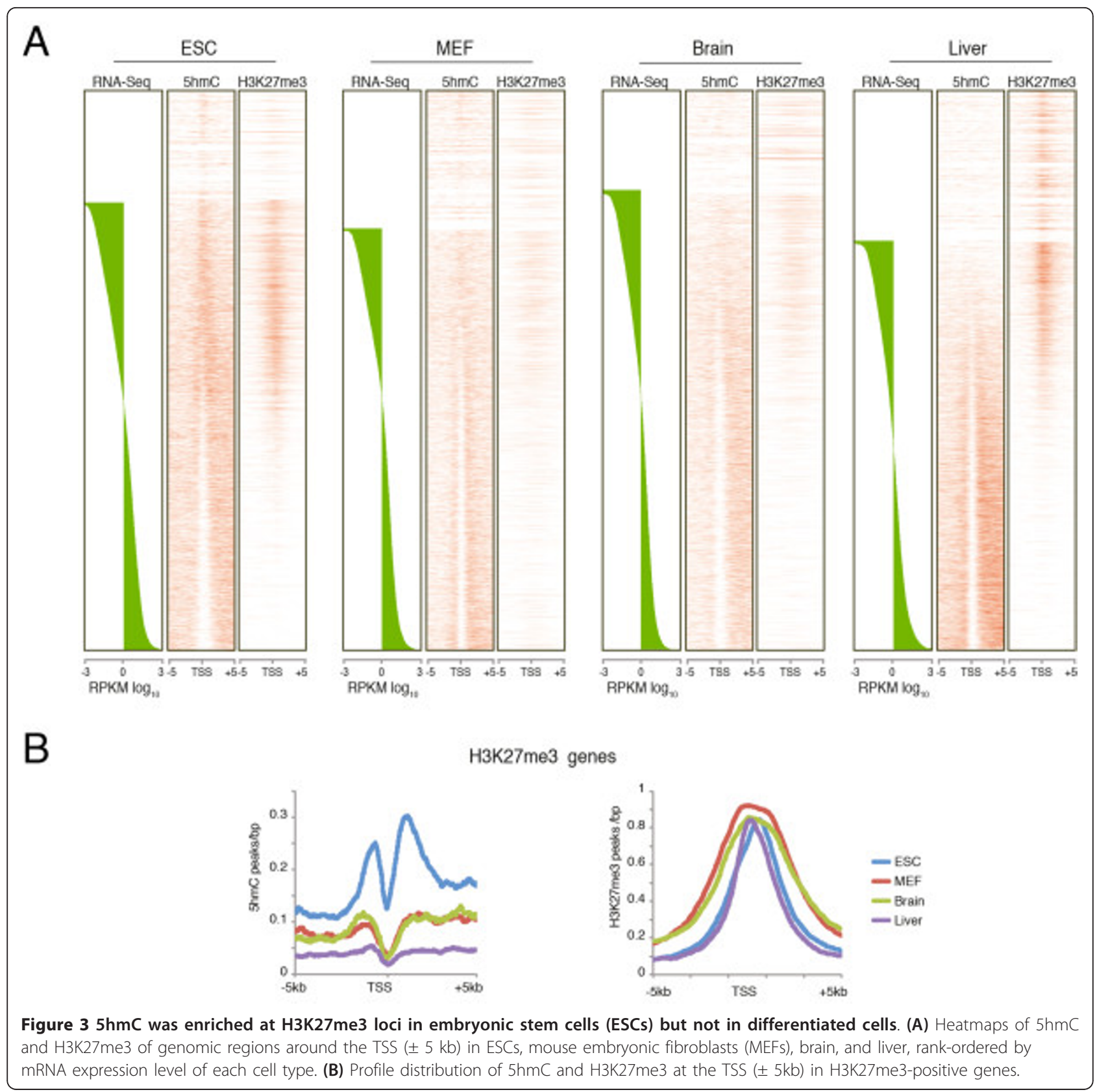

form a complex with PRC2 by co-immunoprecipitation of the endogenous proteins from ESCs and MEFs. Tet1 was co-immunoprecipitated with the PRC2 subunits Suz12 and Ezh2 in ESCs (Figure 5A). The reciprocal immunoprecipitation experiment with a Suz12 antibody showed association of PRC2 with Tet1 (Figure 5B). Notably, we did not observe PRC2 co-immunoprecipitation with Tet1 in MEFs (Figure 5A,B), whereas Sin3a was co-immunoprecipitated with Tet1 in both cell lines, thus confirming that the physical connection between Tet1 and PRC2 complex is limited to ESCs. To test whether the Tet1/PRC2 interaction is necessary for DNA hydroxymethylation at $\mathrm{H} 3 \mathrm{~K} 27 \mathrm{me} 3$ regions, we silenced Suz12 in ESCs using two different small hairpin (sh)RNAs. Both constructs decreased Suz12 protein and H3K27me3 levels without affecting the levels of Tet1 or Sin3a (Figure 5C; see Additional file 1: Figure S3). Suz12 silencing resulted in a significant reduction of global DNA hydroxymethylation (Figure 5D; see Additional file 1: Figure S3).

Genome-wide analysis of $5 \mathrm{hmC}$ profiles in control and Suz12 knockdown ESCs showed a reduction of $5 \mathrm{hmC}$ at the promoter regions of $\mathrm{H} 3 \mathrm{~K} 27 \mathrm{me} 3$-positive genes within the Tet1 co-bound regions but not at H3K27me3-negative regions (Figure 6A,B; see Additional file 1, Figure S4). 


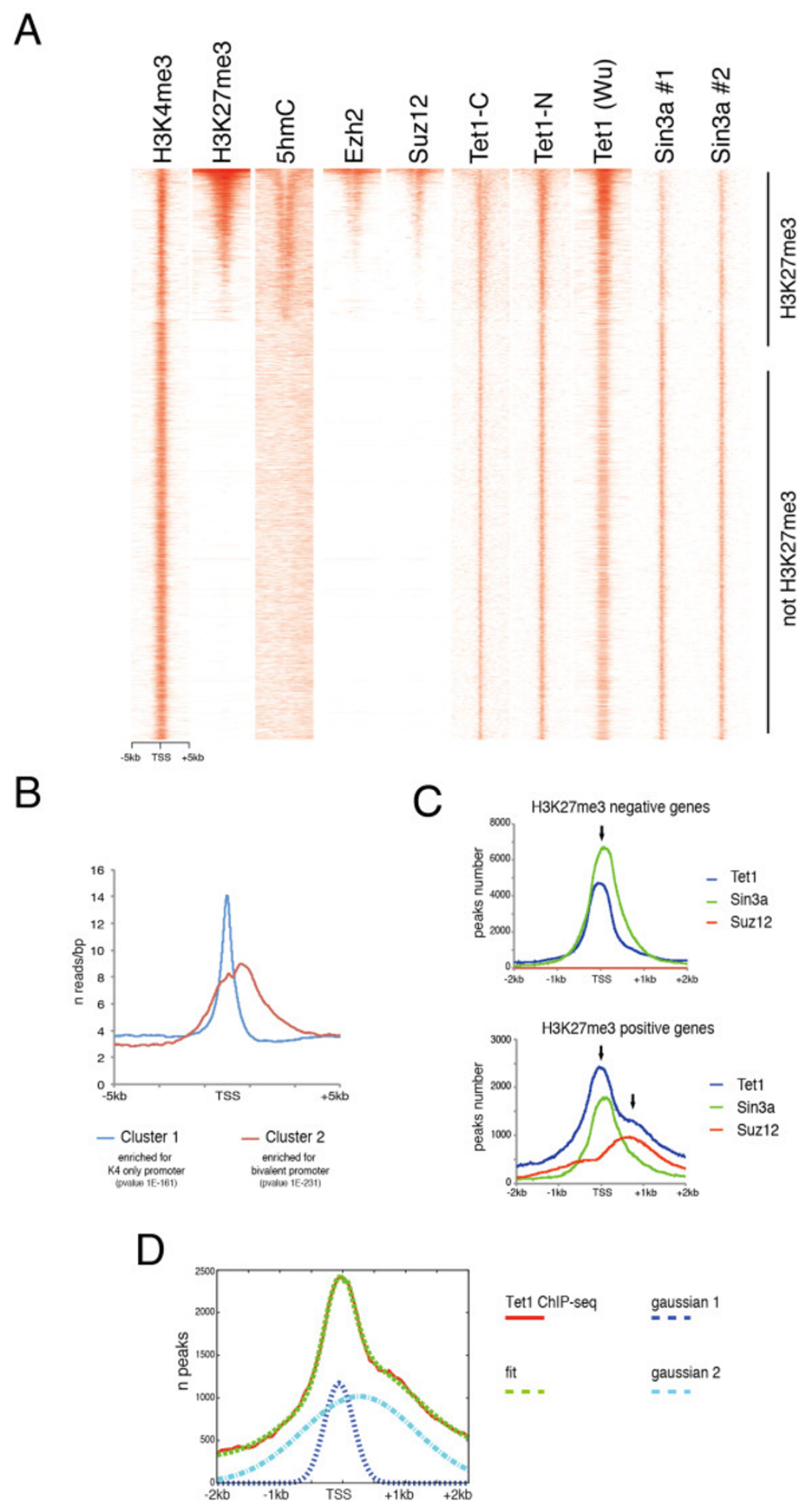

Figure 4 Bimodal distribution of Tet1 on bivalent genes. (A) Heatmaps of H3K4me3, H3K27me3, 5hmC, Ezh2, Suz12, Tet1-C [25], Tet1-N [25], Tet1-Wu [32], Sin3a \#1 (Abcam), and Sin3a \#2 (Santa Cruz Biotechnology) on the transcription start site (TSS) of genes rank-ordered by their H3K27me3 level. (B) Distribution frequency of Tet1 binding obtained by clustering of Tet1 binding data by k-means algorithm revealed two different Tet1 occupancy profiles on gene promoters.(C) Tet1, Sin3a and Suz12 occupancy around the TSS ( \pm 2 kb) of H3K27me3-negative (upper panel) or H3K27me3-positive (lower panel) genes. (D) Fitting of the Tet1 binding in H3K27me3-positive genes revealed two Gaussian profiles, one centered -39 bp upstream from the TSS, and the other centered +455 bp downstream from the TSS. 


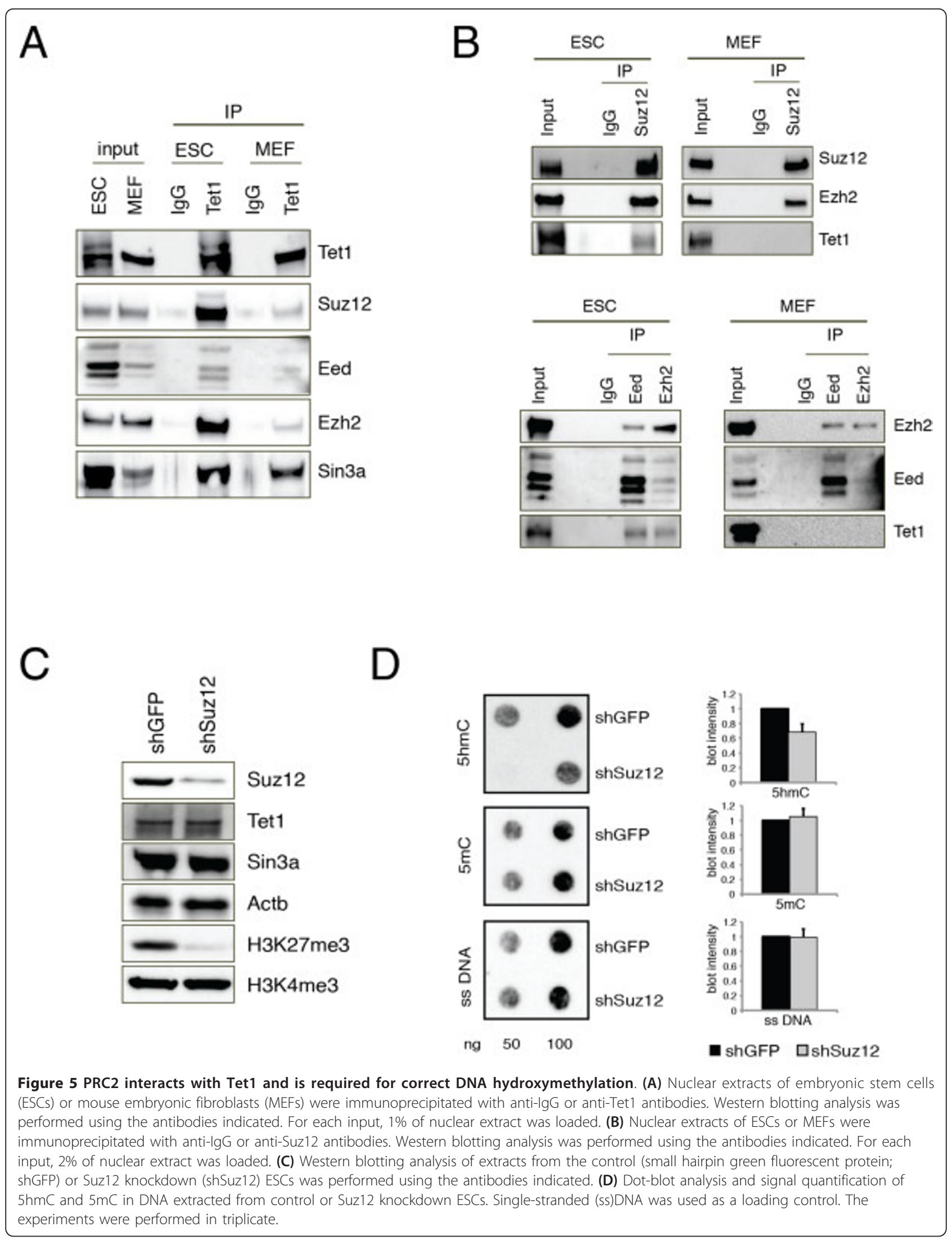


ChIP analysis of Tet1 binding to the bivalent genes $K d r$ and Hoxa1 and the non-bivalent genes Cdc25a and Pou5f1 in wild-type and Suz12-silenced cells showed a reduction of Tet1 binding only at Tet1-PRC2 co-bound regions (Figure 6C; see Additional file 1: Figure S4). Taken together, these results indicate that $\mathrm{PRC} 2$ is required for recruitment of Tet1 and DNA hydroxymethylation on bivalent promoters.

\section{Discussion}

We compared the genome-wide distribution of $5 \mathrm{hmC}$ in ESCs, MEF, and terminally differentiated brain and liver tissues by GLIB-Seq analysis, which identified a similar enrichment of $5 \mathrm{hmC}$ on promoters, enhancers, and gene bodies, with a preference for exons in all cell types. A major difference between ESCs and other cell types is the correlation between $5 \mathrm{hmC}$ and $\mathrm{H} 3 \mathrm{~K} 27 \mathrm{me} 3$, which is unique to ESCs, whereas this correlation is not present in differentiated fibroblasts or in adult tissues. We found that this difference is due to an ESC-specific functional interplay between Tet1 and the PRC2 complex.

We found that in ESCs, but not in differentiated cells, PRC2 recruits Tet1 to the chromatin of bivalent genes to maintain their hypomethylated state. First, through in-depth analysis of previous ChIP-Seq data in ESCs, we found that Tet1 binds to chromatin with two different binding profiles: one, which is characterized by narrow peaks, is centered on the TSS of almost all genes and overlaps with Sin3a, while the other, which is characterized by broader peaks, is centered downstream of the promoters of bivalent genes and overlaps with PRC2. Second, co-immunoprecipitation showed that Tet1 interacts with PRC2 in ESCs but not in fibroblasts. Third, in ESCs, Suz12 silencing affected Tet1 binding and $5 \mathrm{hmC}$ modification at bivalent promoters specifically at PRC2-positive regions but not at other regions.

Thus, our results show that Tet1, besides binding at the TSS together with Sin3a, is recruited by PRC2 downstream from the TSS at bivalent genes. The difference in the peak shape of the two binding profiles is compatible with the different recruitment mechanisms. In one case, Tet1 binds directly to the DNA on the TSS via its CXXC domain, which has high affinity for clustered unmethylated CpG dinucleotides [11], whereas in the other case, Tet 1 is recruited by PRC2 to the chromatin. In this latter case, the binding of Tet1 and the distribution of $5 \mathrm{hmC}$ occupy larger regions, owing to the typical spread of PRC2 binding on bivalent promoters. Interestingly, Tet1, together with Sin3a, localizes to unmethylated TSSs, suggesting that, at these regions, this complex binds to unmethylated $\mathrm{CpG}$ or catalyzes the oxidation of $5 \mathrm{mC}$ to completion. Conversely, Tet1 binding with PRC2 overlaps with $5 \mathrm{hmC}$ on bivalent genes. Thus, our results are compatible with a model by which Tet1-dependent oxidation of $5 \mathrm{mC}$ is finely regulated to either eliminate DNA methylation or generate $5 \mathrm{hmC}$ epigenetic marks in different regions. Previous findings that $\mathrm{MeCP} 2, \mathrm{~Np} 95$, and Mbd3 recognize $5 \mathrm{hmC}[10,43-45]$ imply that this DNA modification can be a specific epigenetic signal.

We found that PRC2 depletion from ESCs reduced Tet1 binding on bivalent promoters. This result differs from previous studies reporting that Ezh2 knockdown did not affect Tet1 binding [32]. This discrepancy could be because depletion of Ezh2 does not impair PRC2 binding to the chromatin or its methylation activity, because in ESCs, Ezh1 can complement Ezh2 function [39]. By contrast, knockdown of Suz12 destabilizes the complex [37].

We found that Tet1/PRC2 co-immunoprecipitation is ESC-specific, as we could not co-immunoprecipitate Tet1 with PRC2 in fibroblasts, and previous experiments failed to detect PRC2 proteins interacting with Tet1 in HEK293 cells [25]. These results suggest that the functional interaction between Tet1 and PRC2 in ESCs is either indirect, possibly mediated by one of the ESC-specific cofactors, or is dependent on post-translation modifications.

We also found that the distribution of $5 \mathrm{hmC}$ on gene bodies is not tissue-specific, but increases with the level of gene expression in all cell types analyzed, suggesting that $5 \mathrm{hmC}$ acts as a positive activator by reducing the $5 \mathrm{mC}$ level. This regulation is confirmed by the recent finding that $5 \mathrm{hmC}$ was increased in gene bodies that were transcriptionally upregulated in a model of neuronal differentiation [46]. However, we found that genes expressed at very high levels showed little or no $5 \mathrm{hmC}$, suggesting that DNA hydroxymethylation is not neutral but is mildly inhibitory on the transcription process. These results agree with in vitro experiments showing that $5 \mathrm{hmC}$ modifications are mildly repressive when present in the gene body [47].

We reported that PRC2 depletion reduced Tet1 binding and the presence of $5 \mathrm{hmC}$ at promoters of bivalent genes in ESCs. A previous report showed that Tet 1 depletion results in the increased methylation and minor binding of PRC2 [32], most likely because Tet1dependent demethylation facilitates PRC2 recruitment to the DNA, as methyl CpG counteracts the binding of PRC2. In fact, genome-wide analysis reported mutual exclusiveness of $\mathrm{H} 3 \mathrm{~K} 27 \mathrm{me} 3$ with DNA methylation in CpG islands [48-51], and DNA methylation inhibits the binding of PRC2 in vitro [50]. Taken together, these results suggest a positive feedback loop between Tet1dependent DNA demethylation and PRC2-dependent repression through $\mathrm{H} 3 \mathrm{~K} 27 \mathrm{me} 3$ in ESCs in order to maintain developmental genes in the poised status. Thus, the presence of these two contrasting epigenetic markers on the same chromatin region is required to allow activation or repression of bivalent genes following action of developmental stimuli. 


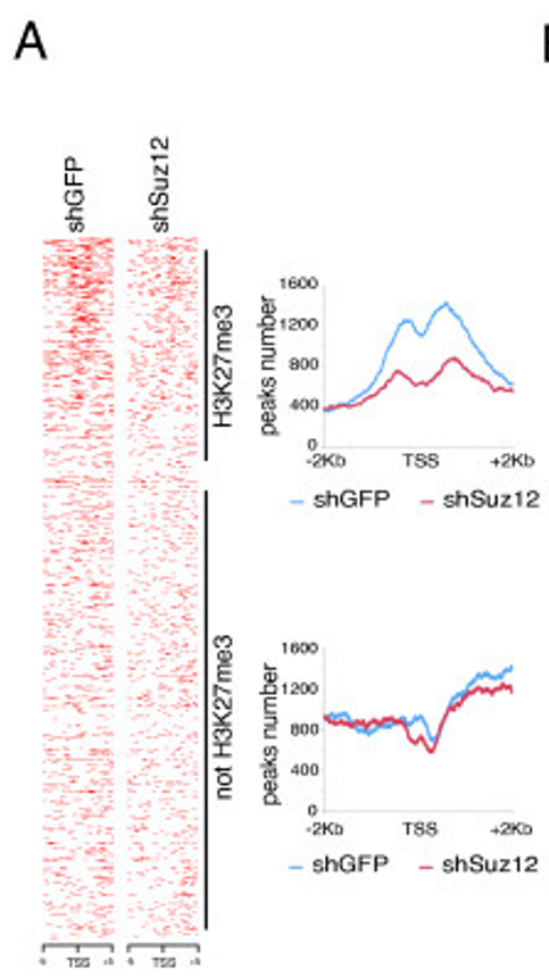

B
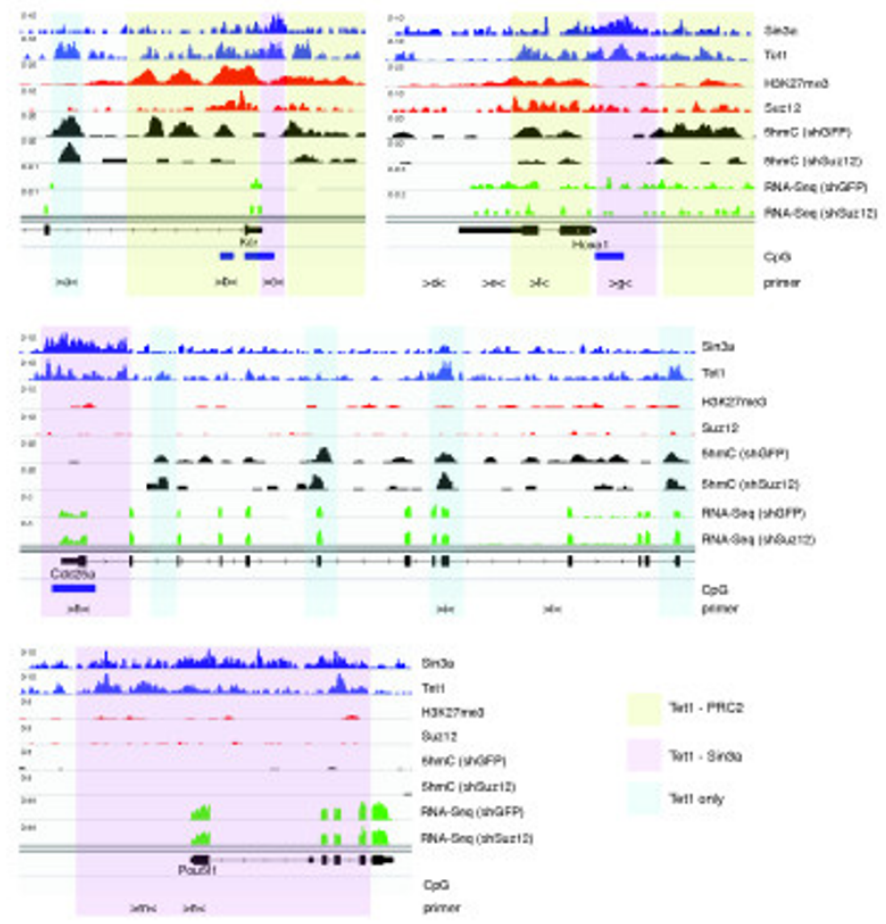

wat1 - Pace

Will - snow

wall and

C

ChIP Tet1
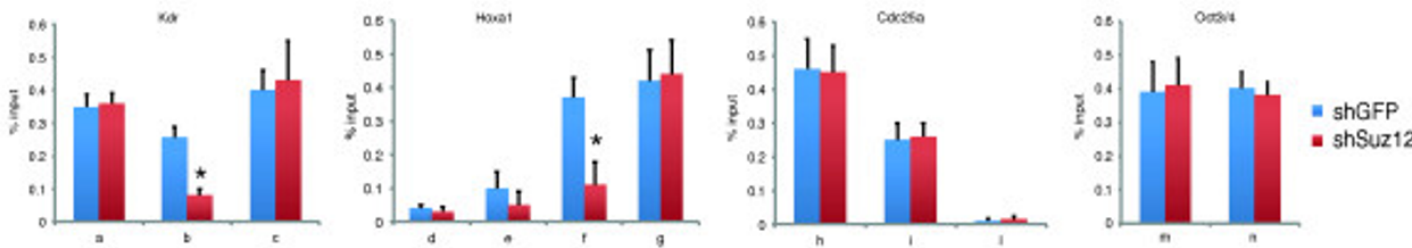

D

MeDIP
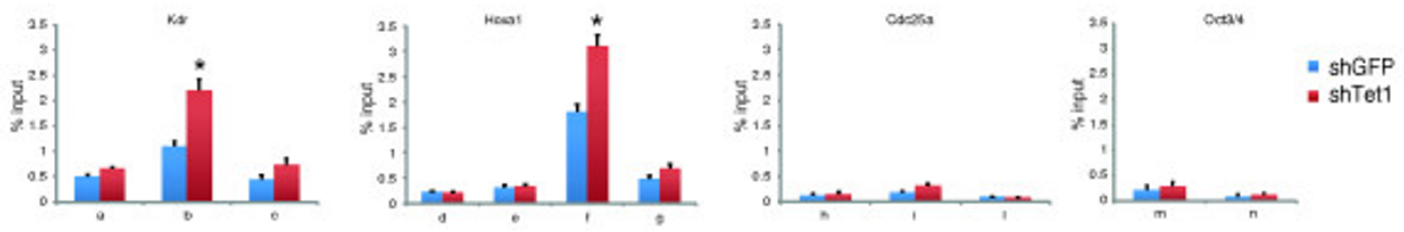

Figure 6 Polycomb repressive complex 2 (PRC2) is required for $5 \mathrm{hmC}$ deposition and Tet1 binding in Tet1-PRC2 co-bound regions. (A) Heatmaps and distribution profiles of $5 \mathrm{hmC}$ around the transcription start site (TSS) of genes rank-ordered by H3K27me3 levels in control or Suz12 knockdown embryonic stem cells (ESCS) See also Figure S3(C-E). (B) Sin3a, Tet1, H3K27me3, Suz12 occupancy and 5hmC occupancy in control and Suz12 knockdown cells on representative examples of bivalent (Kdr and Hoxa1) and K4-only (Cdc25a and Pou5f1) genes. Chromatin immunoprecipitation (ChIP) analysis of Tet1 binding of genomic regions (a to $n$ ) as indicated in panel (A), in control or Suz12 knockdown ESCs $\left({ }^{*} P<0.01\right)$ 


\section{Conclusions}

Using genome-wide analysis, Suz12 silencing, and immunoprecipitation experiments we found that in ESCs, but not in other cell types, PRC2 recruits Tet1 to H3K27me3 regions. Our results identify a novel way by which Tet1 is recruited onto the chromatin, independent of its ability to bind directly to $\mathrm{CpG}$ or to be recruited by Sin3a, and clarify the mechanism that links H3K27me3 modifications on the nucleosome and $5 \mathrm{hmC}$ on the DNA in ESCs. These findings highlight the mechanistic link between PRC2 and Tet1 and contribute to our understanding of how these two epigenetic modifiers regulate the chromatin state of bivalent genes to maintain these bivalent genes in a poised state, ensuring their dynamic regulation during differentiation.

\section{Materials and methods Cell culture}

E14 mouse ES cells were cultured in high-glucose DMEM (Invitrogen Corp., Carlsbad, CA, USA) supplemented with 15\% FBS (Millipore Corp., Billerica, MA, USA), $0.1 \mathrm{mmol} / \mathrm{l}$ nonessential amino acids (Invitrogen), $1 \mathrm{mmol} / \mathrm{l}$ sodium pyruvate (Invitrogen), $0.1 \mathrm{mmol} / \mathrm{l} 2$ mercaptoethanol, $1500 \mathrm{U} / \mathrm{ml}$ Leukemia Inhibitory Factor (LIF; Millipore), $25 \mathrm{U} / \mathrm{ml}$ penicillin, and $25 \mu \mathrm{g} / \mathrm{ml}$ streptomycin. MEFs were derived from 13.5 day pregnant female mice and cultured in high-glucose DMEM supplemented with 10\% FCS. Mouse tissues were extracted from 8-week-old mice. For silencing of Suz12, ESCs were transfected as previously described [52] with the TRCN0000123889 and TRCN0000123891 vectors (Open Biosystems/Thermo Scientific Inc., Ptitsburgh PA, USA) and then maintained for selection for 3 days with $1 \mu \mathrm{g} / \mathrm{ml}$ puromycin.

\section{DNA extraction and GLIB-Seq}

Genomic DNA was extracted using a DNeasy Blood and Tissue kit (Qiagen Inc., Valencia, CA, USA).

GLIB was precipitated using a Hydroxymethyl Collector (Active Motif, Carlsbad, CA, USA). Libraries were generated with a ChIP-Seq Sample Prep Kit (Illumina Inc., San Diego, CA, USA) and sequenced on an HiScanSQ Platform (Illumina).

\section{Bioinformatic analysis}

Sequencing data were mapped to the mouse genome (mm9 assembly) using Bowtie (version 0.12.7), reporting only unique hits with up to two mismatches. Redundancies were collapsed, and peak calling was performed using MACS (version 1.4.1). For comparative analysis, we downloaded GEO Datasets data for the ESC histone modifications GSE12241 [53,54] and GSE11172 [55], and the transcription factors GSE11431 [56], GSE24843 [25], and GSE26833 [19,32]. For histone modifications and mRNA expression, ChIP-Seq and RNA-Seq data on ESCs, MEFs, and brain or liver tissues were downloaded from the ENCODE project database [57], corresponding to the following GEO Datasets: GSE36025, GSE36026, and GSE31039. Datasets for ChIP-Seq of H3K27me3 on MEFs was downloaded from GSE12241.

LCP-ICP-HCP promoters were defined as described by Weber et al. [58], H3K4me3-only and bivalent promoters were defined as described by Ku et al. [59], and active or poised enhancers were defined as previously described $[60,61]$. To obtain three groups of equal size, genes with RPKM less than $0.1,0.1$ to 5 , and less 5 were categorized as having no, low, and medium/high expression, respectively. Liver-specific genes were defined as having RPKM less than 10 in liver and less than 1 in other cells. Housekeeping genes were defined as RPKM greater than 10 in all cell types.

Data mapped on the mouse mm8 assembly was transposed to the $\mathrm{mm} 9$ assembly using the liftOver tool. Heatmaps and comparative analyses were performed using custom Perl scripts. Clustering of Tet1 binding profiles was performed using the MATLAB implementation of the k-means algorithm using the Pearson correlation coefficient as the 'distance' between profiles. Using 100 realizations of the clustering (using different random seeds), we foudn that the composition of clusters was remarkably stable. The fitting procedure of the average Tet1 binding profile was performed using the gnuplot least squares fitting algorithm. The test function was a superposition of two (non-normalized) Gaussian distributions (six parameters fit: two means, two variances, one relative weight, one overall amplitude factor).

\section{Nuclear protein extractions}

Cells were harvested in $1 \times$ PBS and resuspended in isotonic buffer $(20 \mathrm{mmol} / \mathrm{l}$ HEPES pH 7.5, $100 \mathrm{mmol} / \mathrm{l}$ $\mathrm{NaCl}, 250 \mathrm{mmol} / \mathrm{l}$ sucrose, $5 \mathrm{mmol} / \mathrm{l} \mathrm{MgCl}_{2}, 5 \mu \mathrm{mol} / \mathrm{l}$ $\mathrm{ZnCl}_{2}$ ), then cells were resuspended in isotonic buffer supplemented with $1 \% \mathrm{NP}-40$ to isolate nuclei. The isolated nuclei were resuspended in digestion buffer (50 mmol/l Tris- $\mathrm{HCl} \mathrm{pH} 8.0,100 \mathrm{mmol} / \mathrm{l} \mathrm{NaCl}, 250$ $\mathrm{mmol} / \mathrm{l}$ Sucrose, $0.5 \mathrm{mmol} / \mathrm{l} \mathrm{MgCl} 2,5 \mathrm{mmol} / \mathrm{l} \mathrm{CaCl}_{2}$, $5 \mu \mathrm{mol} / \mathrm{l} \mathrm{ZnCl}_{2}$ ), and treated with microccocal nuclease at $30^{\circ} \mathrm{C}$ for $10 \mathrm{~min}$.

\section{Immunoprecipitations}

Nuclear proteins were incubated with $3 \mu \mathrm{g}$ of specific antibody overnight at $4^{\circ} \mathrm{C}$. Immunocomplexes were incubated with Protein G-conjugated magnetic beads (Dynal; Invitrogen) for $2 \mathrm{~h}$ at $4^{\circ} \mathrm{C}$. Samples were washed four times with digestion buffer supplemented with $0.1 \%$ NP-40 at room temperature. Proteins were eluted by incubating with $0.4 \mathrm{M} \mathrm{NaCl}$ TE buffer for $30 \mathrm{~min}$, and analyzed by western blotting as previously described [62]. 


\section{Chromatin immunoprecipitation and dot-blot analysis}

Each ChIP experiment was performed at least three independent times, as previously described [52]. Oligonucleotide sequences are shown in the supplementary data. See Additional file 1. Genomic DNA for the dot-blot analysis was sonicated for 15 cycles and denatured with $0.4 \mathrm{M}$ $\mathrm{NaOH}$, then incubated for 10 minutes at $95^{\circ} \mathrm{C}$ before being spotted onto Hybond ${ }^{\mathrm{TM}}-\mathrm{N}^{+}$membranes (GE Healthcare, Little Chalfont, Buckinghamshire, UK).

\section{Antibodies}

The antibodies used were anti-Tet1, anti-H3K27me3, anti-H3K4me3 (all Millipore), anti-ssDNA (Abcam, Cambridge, MA, USA), anti-Suz12and anti-Ezh2 (bothCell Signaling Technology, Danvers, MA, USA), antiactin (Sigma-Aldrich, St Louis, MO, USA), anti-Sin3a (SantaCruz Biotechnology Inc., Santa Cruz, CA, USA), and anti-5mC and anti-5hmC (both Active Motif).

\section{Data access}

The Gene Expression Omnibus accession number for $5 \mathrm{hmC}$ profiling of ESC, MEF, brain and liver reported in this paper is GSE44566.

\section{Additional material}

Additional file 1: PDF document containing four supplemental figures (Figures S1 to S4), and one supplemental table (Table S1).

\begin{abstract}
Abbreviations
5mC: 5-methylcytosine; 5hmC: 5-hydroxymethylcytosine; ChIP: chromatin immunoprecipitation; Eed: Embryonic ectoderm development; ESC. Embryonic stem cell; Ezh1: Enhancer of Zeste homolog 1; GLIB: Glucosylation: periodate oxidation: biotinylation; HCP: High CpG; ICP: Intemediate CpG; LCP: Low CpG; MEF: Mouse embryonic fibroblast; PRC2. Polycomb repressive complex 2; RPKM: Reads per kb of exon per million mapped reads; Suz12: Suppressor of Zeste 12 homolog; TET: Ten-eleven translocation; TSS: Transcription start site
\end{abstract}

\section{Authors' contributions}

FN and SO designed the experiments and co-wrote the paper. FN and D performed the ChIP-Seq experiments and analyzed the data. AP and RZ contributed to the bioinformatic analysis. AK performed the tissue preparations and the biochemical experiments. CP and SR contributed to cell culture and DNA cloning. All authors read and approved the final manuscript.

\section{Acknowledgements}

This work was supported by the Associazione Italiana Ricerca sul Cancro (AIRC), Regione Toscana programma salute, and Ministero della Salute Bando Cellule Staminali.

\section{Authors' details}

${ }^{1}$ Human Genetics Foundation (HuGeF), via Nizza 52, 10126, Torino, Italy. 2 Dipartimento di Biotecnologie Chimica e Farmacia Università degli Studi di Siena. Via Fiorentina 1, 53100 Siena, Italy. ${ }^{3}$ Politecnico di Torino, Corso Duca degli Abruzzi 24, I-10129 Torino, Italy.

Received: 28 March 2013 Revised: 10 August 2013 Accepted: 29 August 2013 Published: 29 August 2013

\section{References}

1. Bestor TH: The DNA methyltransferases of mammals. Hum Mol Genet 2000, 9:2395-2402

2. Li E: Chromatin modification and epigenetic reprogramming in mammalian development. Nat Rev Genet 2002, 3:662-673.

3. Reik W, Walter J: Genomic imprinting: parental influence on the genome. Nat Rev Genet 2001, 2:21-32.

4. Tahiliani M, Koh KP, Shen Y, Pastor WA, Bandukwala H, Brudno Y, Agarwal S, lyer LM, Liu DR, Aravind L, Rao A: Conversion of 5-methylcytosine to 5hydroxymethylcytosine in mammalian DNA by MLL partner TET1. Science 2009, 324:930-935.

5. Kriaucionis S, Heintz N: The nuclear DNA base 5-hydroxymethylcytosine is present in Purkinje neurons and the brain. Science 2009, 324:929-930.

6. Ito S, D'Alessio AC, Taranova OV, Hong K, Sowers LC, Zhang Y: Role of Tet proteins in $5 \mathrm{mC}$ to $5 \mathrm{hmC}$ conversion, ES-cell self-renewal and inner cell mass specification. Nature 2010, 466:1129-1133.

7. Chen ZX, Riggs AD: DNA methylation and demethylation in mammals. $J$ Biol Chem 2011, 286:18347-18353.

8. Cortázar D, Kunz C, Selfridge J, Lettieri T, Saito Y, MacDougall E, Wirz A, Schuermann D, Jacobs AL, Siegrist F, Steinacher R, Jiricny J, Bird A, Schär P: Embryonic lethal phenotype reveals a function of TDG in maintaining epigenetic stability. Nature 2011, 470:419-423.

9. Prensner JR, Chinnaiyan AM: Metabolism unhinged: IDH mutations in cancer. Nat Med 2011, 17:291-293.

10. Mellén M, Ayata P, Dewell S, Kriaucionis S, Heintz N: MeCP2 binds to $5 \mathrm{hmC}$ enriched within active genes and accessible chromatin in the nervous system. Cell 2012, 151:1417-1430.

11. Wu H, Zhang Y: Mechanisms and functions of Tet protein-mediated 5methylcytosine oxidation. Genes Dev 2011, 25:2436-2452.

12. Haffner MC, Chaux A, Meeker AK, Esopi DM, Gerber J, Pellakuru LG, Toubaji A, Argani P, lacobuzio-Donahue C, Nelson WG, Netto GJ, De Marzo AM, Yegnasubramanian S: Global 5-hydroxymethylcytosine content is significantly reduced in tissue stem/progenitor cell compartments and in human cancers. Oncotarget 2011, 2:627-637.

13. Jin SG, Jiang Y, Qiu R, Rauch TA, Wang Y, Schackert G, Krex D, Lu Q, Pfeifer GP: 5-Hydroxymethylcytosine is strongly depleted in human cancers but its levels do not correlate with IDH1 mutations. Cancer Res 2011, 71:7360-7365.

14. Kudo Y, Tateishi K, Yamamoto K, Yamamoto S, Asaoka Y, ljichi H, Nagae G, Yoshida $H$, Aburatani $H$, Koike K: Loss of 5-hydroxymethylcytosine is accompanied with malignant cellular transformation. Cancer Sci 2012, 103:670-676.

15. Lian CG, Xu Y, Ceol C, Wu F, Larson A, Dresser K, Xu W, Tan L, Hu Y, Zhan Q, Lee C-W, Di Hu, Lian BQ, Kleffel S, Yang Y, Neiswender J, Khorasani AJ, Fang R, Lezcano C, Duncan LM, Scolyer RA, Thompson JF, Kakavand H, Houvras Y, Zon LI, Mihm MC Jr, Kaiser UB, Schatton T, Woda BA, Murphy GF, et al: Loss of 5-hydroxymethylcytosine is an epigenetic hallmark of melanoma. Cell 2012, 150:1135-1146.

16. Szulwach KE, Li X, Li Y, Song C-X, Wu H, Dai Q, Irier H, Upadhyay AK, Gearing M, Levey Al, Vasanthakumar A, Godley LA, Chang Q, Cheng X, He C, Jin P: 5-hmC-mediated epigenetic dynamics during postnatal neurodevelopment and aging. Nature Neuroscience 2011, 14:1607-1616.

17. Yang H, Liu Y, Bai F, Zhang J-Y, Ma S-H, Liu J, Xu Z-D, Zhu H-G, Ling Z-Q, Ye $D$, Guan $K-L$, Xiong $Y$ : Tumor development is associated with decrease of TET gene expression and 5-methylcytosine hydroxylation. 2013, 32:669-669.

18. Pastor WA, Pape UJ, Huang Y, Henderson HR, Lister R, Ko M, McLoughlin EM, Brudno Y, Mahapatra S, Kapranov P, Tahiliani M, Daley GQ, Liu XS, Ecker JR, Milos PM, Agarwal S, Rao A: Genome-wide mapping of 5hydroxymethylcytosine in embryonic stem cells. Nature 2011, 473:394-397.

19. Wu H, D'Alessio AC, Ito S, Wang Z, Cui K, Zhao K, Sun YE, Zhang Y: Genome-wide analysis of 5-hydroxymethylcytosine distribution reveals its dual function in transcriptional regulation in mouse embryonic stem cells. Genes Dev 2011, 25:679-684.

20. Xu Y, Wu F, Tan L, Kong L, Xiong L, Deng J, Barbera AJ, Zheng L, Zhang $H$, Huang S, Min J, Nicholson T, Chen T, Xu G, Shi Y, Zhang K, Shi YG: Genome-wide regulation of $5 \mathrm{hmC}, 5 \mathrm{mC}$, and gene expression by tet 1 hydroxylase in mouse embryonic stem cells. Mol Cell 2011, 42:451-464

21. Matarese F, Pau EC-DS, Stunnenberg HG: 5-Hydroxymethylcytosine: a new kid on the epigenetic block\&quest. Mol Syst Biol 2011, 7:1-9. 
22. Stroud H, Feng S, Kinney SM, Pradhan S, Jacobsen SE: 5Hydroxymethylcytosine is associated with enhancers and gene bodies in human embryonic stem cells. Genome Biol 2011, 12:R54.

23. Szulwach KE, Li X, Li Y, Song C-X, Han JW, Kim S, Namburi S, Hermetz K, Kim JJ, Rudd MK, Yoon Y-S, Ren B, He C, Jin P: Integrating 5Hydroxymethylcytosine into the Epigenomic Landscape of Human Embryonic Stem Cells. PLoS Genet 2011, 7:e1002154.

24. Booth MJ, Branco MR, Ficz G, Oxley D, Krueger F, Reik W, Balasubramanian S: Quantitative sequencing of 5-methylcytosine and 5hydroxymethylcytosine at single-base resolution. Science 2012, 336:934-937.

25. Williams K, Christensen J, Pedersen MT, Johansen JV, Cloos PAC, Rappsilber J, Helin K: TET1 and hydroxymethylcytosine in transcription and DNA methylation fidelity. Nature 2011, 473:343-348.

26. Yu M, Hon GC, Szulwach KE, Song C-X, Zhang L, Kim A, Li X, Dai Q, Shen Y, Park B, Min J-H, Jin P, Ren B, He C: Base-resolution analysis of 5hydroxymethylcytosine in the mammalian genome. Cell 2012, 149:1368-1380

27. Song C-X, Szulwach KE, Fu Y, Dai Q, Yi C, Li X, Li Y, Chen C-H, Zhang W, Jian X, Wang J, Zhang L, Looney TJ, Zhang B, Godley LA, Hicks LM, Lahn BT, Jin $P$, He C: Selective chemical labeling reveals the genome-wide distribution of 5-hydroxymethylcytosine. Nat Biotechnol 2010, 29:68-72.

28. Dawlaty MM, Ganz K, Powell BE, Hu Y-C, Markoulaki S, Cheng AW, Gao Q, Kim J, Choi S-W, Page DC, Jaenisch R: Tet1 Is dispensable for maintaining pluripotency and its loss is compatible with embryonic and postnatal development. Cell Stem Cell 2011, 9:166-175

29. Ficz G, Branco MR, Seisenberger S, Santos F, Krueger F, Hore TA, Marques CJ, Andrews S, Reik W: Dynamic regulation of 5hydroxymethylcytosine in mouse ES cells and during differentiation. Nature 2011, 473:398-402

30. Freudenberg JM, Ghosh S, Lackford BL, Yellaboina S, Zheng X, Li R, Cuddapah S, Wade PA, Hu G, Jothi R: Acute depletion of Tet1-dependent 5-hydroxymethylcytosine levels impairs LIF/Stat3 signaling and results in loss of embryonic stem cell identity. Nucleic Acids Res 2012, 40:3364-3377.

31. Koh KP, Yabuuchi A, Rao S, Huang Y, Cunniff K, Nardone J, Laiho A, Tahiliani M, Sommer CA, Mostoslavsky G, Lahesmaa R, Orkin SH, Rodig SJ, Daley GQ, Rao A: Tet1 and Tet2 regulate 5-hydroxymethylcytosine production and cell lineage specification in mouse embryonic stem cells. Stem Cell 2011, 8:200-213.

32. Wu H, D'Alessio AC, Ito S, Xia K, Wang Z, Cui K, Zhao K, Sun YE, Zhang Y: Dual functions of Tet1 in transcriptional regulation in mouse embryonic stem cells. Nature 2011, 473:389-393.

33. Simon JA, Kingston RE: Mechanisms of polycomb gene silencing: knowns and unknowns. Nat Rev Mol Cell Biol 2009, 10:697-708.

34. Ringrose $L$, Paro R: Polycomb/Trithorax response elements and epigenetic memory of cell identity. Development 2007, 134:223-232.

35. Li G, Margueron R, Ku M, Chambon P, Bernstein BE, Reinberg D: Jarid2 and PRC2, partners in regulating gene expression. Genes Dev 2010, 24:368-380.

36. Margueron R, Reinberg D: The polycomb complex PRC2 and its mark in life. Nature 2011, 469:343-349.

37. Pasini D, Bracken AP, Hansen JB, Capillo M, Helin K: The polycomb group protein Suz12 is required for embryonic stem cell differentiation. $\mathrm{Mol}$ Cell Biol 2007, 27:3769-3779.

38. Pasini D, Cloos PAC, Walfridsson J, Olsson L, Bukowski J-P, Johansen JV, Bak M, Tommerup N, Rappsilber J, Helin K: JARID2 regulates binding of the Polycomb repressive complex 2 to target genes in ES cells. Nature 2010, 464:306-310

39. Shen X, Liu Y, Hsu Y-J, Fujiwara Y, Kim J, Mao X, Yuan G-C, Orkin SH: EZH1 mediates methylation on histone $\mathrm{H} 3$ Lysine 27 and complements $\mathrm{EZH} 2$ in maintaining stem cell identity and executing pluripotency. $\mathrm{Mol} \mathrm{Cell}$ 2008, 32:491-502.

40. Walker E, Chang WY, Hunkapiller J, Cagney G, Garcha K, Torchia J, Krogan NJ, Reiter JF, Stanford WL: Polycomb-like 2 associates with PRC2 and regulates transcriptional networks during mouse embryonic stem cell self-renewal and differentiation. Cell Stem Cell 2010, 6:153-166.

41. Zhang Z, Jones A, Sun C-W, Li C, Chang C-W, Joo H-Y, Dai Q, Mysliwiec MR, Wu L-C, Guo Y, Yang W, Liu K, Pawlik KM, Erdjument-Bromage H, Tempst P, Lee $Y$, Min J, Townes TM, Wang H: PRC2 complexes with JARID2, MTF2, and esPRC2p48 in ES cells to modulate ES cell pluripotency and somatic cell reprogramming. Stem Cells 2011, 29:229-240.
42. Simon JA, Lange CA: Roles of the EZH2 histone methyltransferase in cancer epigenetics. Mut Res 2008, 647:21-29.

43. Yildirim O, Li R, Hung J-H, Chen PB, Dong X, Ee L-S, Weng Z, Rando OJ, Fazzio TG: Mbd3/NURD complex regulates expression of 5hydroxymethylcytosine marked genes in embryonic stem Cells. Cell 2011, 147:1498-1510

44. Frauer C, Hoffmann T, Bultmann S, Casa V, Cardoso MC, Antes I, Leonhardt H: Recognition of 5-hydroxymethylcytosine by the Uhrf1 SRA domain. PLOS ONE 2011, 6:e21306.

45. Zhang Y, Ng HH, Erdjument-Bromage H, Tempst P, Bird A, Reinberg D: Analysis of the NuRD subunits reveals a histone deacetylase core complex and a connection with DNA methylation. Genes Dev 1999, 13:1924-1935.

46. Hahn MA, Qiu R, Wu X, Li AX, Zhang H, Wang J, Jui J, Jin S-G, Jiang Y, Pfeifer GP, Lu Q: Dynamics of 5-hydroxymethylcytosine and chromatin marks in mammalian neurogenesis. Cell Rep 2013, 1-10.

47. Robertson J, Robertson AB, Klungland A: The presence of 5hydroxymethylcytosine at the gene promoter and not in the gene body negatively regulates gene expression. Biochem Biophys Res Comm 2011, 411:40-43.

48. Lindroth AM, Park YJ, McLean CM, Dokshin GA, Persson JM, Herman H, Pasini D, Miró X, Donohoe ME, Lee JT, Helin K, Soloway PD: Antagonism between DNA and H3K27 Methylation at the Imprinted Rasgrf1 Locus. PLOS Genet 2008, 4:e1000145

49. Wu H, Coskun V, Tao J, Xie W, Ge W, Yoshikawa K, Li E, Zhang Y, Sun YE: Dnmt3a-dependent nonpromoter DNA methylation facilitates transcription of neurogenic genes. Science 2010, 329:444-448.

50. Bartke T, Vermeulen M, Xhemalce B, Robson SC, Mann M, Kouzarides T: Nucleosome-interacting proteins regulated by DNA and histone methylation. Cell 2010, 143:470-484

51. Brinkman AB, Gu H, Bartels SJJ, Zhang Y, Matarese F, Simmer F, Marks $H$, Bock C, Gnirke A, Meissner A, Stunnenberg HG: Sequential ChIP-bisulfite sequencing enables direct genome-scale investigation of chromatin and DNA methylation cross-talk. Genome Res 2012, 22:1128-1138.

52. Neri F, Zippo A, Krepelova A, Cherubini A, Rocchigiani M, Oliviero S: Myc regulates the transcription of the PRC2 gene to control the expression of developmental genes in embryonic stem cells. Mol Cell Biol 2012 32:840-851.

53. Mikkelsen TS, Ku M, Jaffe DB, Issac B, Lieberman E, Giannoukos G, Alvarez P, Brockman W, Kim T-K, Koche RP, Lee W, Mendenhall E, O'Donovan A, Presser A, Russ C, Xie X, Meissner A, Wernig M, Jaenisch R, Nusbaum C, Lander ES, Bernstein BE: Genome-wide maps of chromatin state in pluripotent and lineage-committed cells. Nature 2007, 448:553-560.

54. Goren A, Ozsolak F, Shoresh N, Ku M, Adli M, Hart C, Gymrek M, Zuk O, Regev A, Milos PM, Bernstein BE: Chromatin profiling by directly sequencing small quantities of immunoprecipitated DNA. Nat Meth 2010, 7:47-49.

55. Meissner A, Mikkelsen TS, Gu H, Wernig M, Hanna J, Sivachenko A, Zhang X, Bernstein BE, Nusbaum C, Jaffe DB, Gnirke A, Jaenisch R, Lander ES: Genome-scale DNA methylation maps of pluripotent and differentiated cells. Nature 2008, 454:766-770

56. Chen $X, X u H$, Yuan $P$, Fang $F$, Huss $M$, Vega VB, Wong $E$, Orlov $Y L$, Zhang W, Jiang J, Loh Y-H, Yeo HC, Yeo ZX, Narang V, Govindarajan KR, Leong B, Shahab A, Ruan Y, Bourque G, Sung WK, Clarke ND, Wei CL, $\mathrm{Ng} \mathrm{HH}$ : Integration of external signaling pathways with the core transcriptional network in embryonic stem cells. Cell 2008, 133:1106-1117.

57. Consortium TEP, Consortium TEP, data analysis coordination OC, data production $D P L$, data analysis $L A$, group $W$, scientific management NPM, steering committee PI, Boise State University and University of North Carolina at Chapel Hill Proteomics groups (data production and analysis), Broad Institute Group (data production and analysis), Cold Spring Harbor, University of Geneva, Center for Genomic Regulation, Sanger Institute, University of Lausanne, Genome Institute of Singapore group (data production and analysis), Data coordination center at UC Santa Cruz (production data coordination), Duke University, University of Texas, University of North Carolina-Chapel Hill group (data production and analysis), Genome Institute of Singapore group (data production and analysis), HudsonAlpha Institute, UC Irvine, Stanford group (data production and analysis), targeted experimental validation LBNLG, data production and analysis NG, Sanger Institute, Washington University, Yale University, Center for Genomic Regulation, University of Lausanne, CNIO group (data 
production and analysis), University of Massachusetts Medical School, University of Southern California/UC Davis group (data production and analysis), University of Albany SUNY group (data production and analysis), University of Chicago, Stanford group (data production and analysis), University of Heidelberg group (targeted experimental validation), University of Massachusetts Medical School Bioinformatics group (data production and analysis), University of Massachusetts Medical School Genome Folding group (data production and analysis), University of Washington, University of Massachusetts Medical Center group (data production and analysis), Data Analysis Center (data analysis): An integrated encyclopedia of DNA elements in the human genome. Nature 2012, 488:57-74.

58. Weber M, Hellmann I, Stadler MB, Ramos L, Pääbo S, Rebhan M, Schübeler D: Distribution, silencing potential and evolutionary impact of promoter DNA methylation in the human genome. Nat Genet 2007 39:457-466.

59. Ku M, Koche RP, Rheinbay E, Mendenhall EM, Endoh M, Mikkelsen TS, Presser A, Nusbaum C, Xie X, Chi AS, Adli M, Kasif S, Ptaszek LM, Cowan CA, Lander ES, Koseki H, Bernstein BE: Genomewide analysis of PRC1 and PRC2 occupancy identifies two classes of bivalent domains. PLoS Genet 2008, 4:e1000242.

60. Creyghton MP, Cheng AW, Welstead GG, Kooistra T, Carey BW, Steine EJ, Hanna J, Lodato MA, Frampton GM, Sharp PA, Boyer LA, Young RA, Jaenisch R: Histone H3K27ac separates active from poised enhancers and predicts developmental state. Proc Natl Acad Sci USA 2010, 107:21931-21936.

61. Heintzman ND, Hon GC, Hawkins RD, Kheradpour P, Stark A, Harp LF, Ye Z, Lee LK, Stuart RK, Ching CW, Ching KA, Antosiewicz-Bourget JE, Liu H, Zhang X, Green RD, Lobanenkov W, Stewart R, Thomson JA, Crawford GE, Kellis $M$, Ren $B$ : Histone modifications at human enhancers reflect global cell-type-specific gene expression. Nature 2009, 459:108-112.

62. Orlandini $\mathrm{M}$, Semboloni $\mathrm{S}$, Oliviero $\mathrm{S}$ : Beta-catenin inversely regulates vascular endothelial growth factor-d mrna stability. J Biol Chem 2003, 278:44650-44656.

doi:10.1186/gb-2013-14-8-r91

Cite this article as: Neri et al:: Genome-wide analysis identifies a functional association of Tet 1 and Polycomb repressive complex 2 in mouse embryonic stem cells. Genome Biology 2013 14:R91.

\section{Submit your next manuscript to BioMed Central and take full advantage of:}

- Convenient online submission

- Thorough peer review

- No space constraints or color figure charges

- Immediate publication on acceptance

- Inclusion in PubMed, CAS, Scopus and Google Scholar

- Research which is freely available for redistribution

Submit your manuscript at www.biomedcentral.com/submit
Biomed Central 